American Journal of Pharmaceutical Education 2019; 83 (7) Article 6920.

\title{
RESEARCH
}

\section{Assessment of a Faculty and Preceptor Development Intervention to Foster Self-Awareness and Self-Confidence}

\author{
Stephanie C. Shealy, PharmD, ${ }^{a}$ Cathy L. Worrall, PharmD, ${ }^{b}$ Jennifer L. Baker, PharmD, ${ }^{a}$ \\ Amy D. Grant, PharmD, ${ }^{a}$ Patricia H. Fabel, PharmD, ${ }^{a}$ C. Matthew Walker, PharmD, ${ }^{\mathrm{c}}$ \\ Bryan Ziegler, PharmD, ${ }^{a}$ Whitney D. Maxwell, PharmD ${ }^{\mathrm{a}}$ \\ ${ }^{a}$ University of South Carolina College of Pharmacy, Columbia, South Carolina \\ ${ }^{\mathrm{b}}$ Medical University of South Carolina College of Pharmacy, Charleston, South Carolina \\ ${ }^{\mathrm{c}}$ Rite Aid Pharmacy, Camp Hill, Pennsylvania \\ Submitted December 15, 2017; accepted June 14, 2018; published September 2019.
}

Objective. To conduct and evaluate the outcomes of a pharmacy faculty and preceptor development program to foster self-awareness and self-confidence.

Methods. A faculty and preceptor development intervention was implemented in a multi-campus college of pharmacy to promote and assess for improvements in self-awareness and self-confidence. Faculty members and preceptors were surveyed regarding their self-perceptions and confidence at baseline and following an intervention in which they completed the Birkman Method self-assessment and participated in a training program with an active-learning component. A longitudinal follow-up survey was conducted to assess the long-term impacts of the intervention.

Results. Faculty members and preceptors experienced significant improvements in self-awareness from baseline following the development intervention. They also experienced increases in self-confidence related to coaching. A survey evaluating the longitudinal impact of the intervention indicated a positive association between receiving a sufficient level of Birkman Method training and improved ability of both faculty members and preceptors to manage professional relationships. Similarly, a positive association was identified between the sufficiency of training and preceptors' confidence in their ability to manage personal relationships and stress following the intervention.

Conclusion. Faculty members and preceptors teach students to be more self-aware and confident, yet both groups often need to grow in these areas themselves. A faculty and preceptor development intervention using the Birkman Method self-assessment is one approach to facilitating growth in these educators' self-awareness and self-confidence.

Keywords: self-awareness, faculty development, preceptor development, Birkman Method, professional development

\section{INTRODUCTION}

Faculty members and preceptors are directly responsible for mentoring pharmacy students in curricular components related to the affective domain, which includes internal attitudes, behaviors, and values that impact learning. ${ }^{1}$ Given the current emphasis on these components, faculty members and preceptors may also need development in these areas. Standard 4 of the 2016 Accreditation

Corresponding Author: Whitney D. Maxwell, University of South Carolina College of Pharmacy, 715 Sumter St., Columbia, SC 29208. Tel: 803-777-4715. Fax: 803-777-2820. E-mail: maxwell@cop.sc.edu

Note: Stephanie Shealy is a recent PharmD graduate who was enrolled at the South Carolina College of Pharmacy at the University of South Carolina during the study period.
Standards ("Standards 2016") of the Accreditation Council for Pharmacy Education (ACPE) outlines key elements of personal and professional development in students that must be accomplished by the pharmacy curriculum, including self-awareness. ${ }^{2}$ Presently, there is limited literature describing programs to foster selfawareness in pharmacy and other health professions students. ${ }^{3,4-7}$ There is currently no literature describing development programs for faculty members or preceptors that emphasize self-awareness. Ideally, colleges of pharmacy would embrace a culture that promotes selfawareness across all educators within both the didactic and experiential curricula.

The qualitative factors of faculty and staff members are described in the ACPE Standards 2016. According to 


\section{American Journal of Pharmaceutical Education 2019; 83 (7) Article 6920.}

Standard 19.5, a college of pharmacy must “... provide opportunities for career and professional development of its faculty and staff, individually and collectively, to enhance their roles-related skills, scholarly productivity, and leadership." ${ }^{2}$ Faculty development programs within pharmacy education are well-documented. Many faculty development programs emphasize mentoring programs for faculty members. ${ }^{8-10}$ Mentorship has been an emphasis of faculty development programs in colleges of medicine as well. ${ }^{11,12}$ However, in medical schools, growth of faculty self-awareness is also emphasized. ${ }^{13}$ Several medical faculty development programs have identified improvements in faculty self-awareness as a program outcome measure. ${ }^{14-16}$ Significant improvements in selfawareness have previously been used as a marker of successful medical school faculty development. ${ }^{14}$ In contrast, self-awareness has not yet become a high-priority outcome for pharmacy faculty development programs.

ACPE Standard 20 focuses on the qualifications and involvement of preceptors. ${ }^{2}$ Because approximately $30 \%$ of pharmacy education is expected to be delivered by preceptors, development of these individuals remains an important priority in pharmacy education. ${ }^{17}$ Preceptor development programs have been well-documented in the literature, with most emphasizing assessment, learning styles, and continuous professional development of preceptors. ${ }^{18-20}$ However, the impact of a preceptor development program emphasizing preceptor self-awareness has not been published to date.

Although improvements in faculty and preceptor selfawareness resulting from development programs have not been documented in the literature, this is not the case for self-confidence. A common outcome measure of faculty development initiatives in pharmacy, nursing, and medical programs is improvement in the self-confidence of the educator. ${ }^{21-23}$ The same is true for preceptor development initiatives in pharmacy, nursing, and medical education programs. ${ }^{24-26}$ Thus, we incorporated this outcome measure in our assessment of the impact of the Birkman Method faculty and preceptor development intervention we implemented at our institution.

The Birkman Method is a validated self-assessment instrument. ${ }^{27}$ The 298-question assessment is used to describe individuals' communication and behavior styles as well as the types of communication and behaviors each individual needs to receive from others to prevent personal stress. The Birkman Method assessment categorizes communication as "direct" or "indirect" and behavior as "task-oriented" or "people-oriented." Communication and behavior styles under both usual and stressful circumstances are described. The degree to which the communication and behavior styles fall into each category is determined, and a corresponding point is placed on a color-coded Birkman Lifestyle Grid. Each quadrant of the grid represents one of four personality types: red, green, blue, and yellow. The color classification is based on the communication and behavior styles determined for each person through testing to determine a variety of their personality components. Blue and green styles exhibit people-oriented behavior, and red and green styles exhibit task-oriented behavior. Red and green styles include direct communicators, and blue and yellow styles include indirect communicators. ${ }^{27}$ Upon completion of the assessment, The Birkman Method provides a 41-page report describing an individual's behavior and communication under usual and stressful circumstances and detailed explanations of each of the individual's personality components that contributed to the determination of their usual and stressed behavior and communication styles, including their color classifications (red vs green vs blue vs yellow). In addition, the report describes an individual's interests as red (outdoor/scientific/technical), green (persuasive/social/service), yellow (administrative/ numerical), or blue (artistic/literary/musical). A Coaching Page is also included to provide insight on the individual's preferred method of providing and receiving feedback, as well as how their preferred method of providing feedback may be received by those who fall in other color classifications. Birkman Method training programs are provided by certified trainers to help those who complete the assessment to interpret and learn how to apply the results in personal and professional relationships. A detailed explanation of the validation procedures used to ensure testretest reliability, internal consistency, and the convergent and divergent construct validity of the Birkman Method assessment has been published previously., ${ }^{3,28}$

Prior use of the validated Birkman Method assessment in a sample of pharmacy students has demonstrated significant increases in self-awareness, where self-awareness increases were defined as improved alignment between an individual's self-perceptions and external perceptions (eg, generated by the Birkman Method) about that individual. ${ }^{3}$ Thus, we implemented a Birkman Method development intervention for preceptors and faculty members, with the aim of increasing self-confidence and selfawareness among key educators associated with the college. The purpose of this study was to evaluate the impact of a Birkman Method development intervention on faculty and preceptor self-awareness through evaluation of self-perception accuracy. The secondary aim was to determine the impact of the intervention on participants' self-confidence in their awareness of personality-related preferences and their self-confidence in coaching and leadership abilities. We also evaluated the longitudinal 


\section{American Journal of Pharmaceutical Education 2019; 83 (7) Article 6920.}

outcomes of the interventions, including identification of correlations between sufficiency of training received and the likelihood of faculty members and preceptors to use the information and their self-confidence in applying the information in professional and personal settings.

\section{METHODS}

The Institutional Review Board of the University of South Carolina approved this study as exempt research. All active clinical pharmacy faculty members at the South Carolina College of Pharmacy who were not a part of the research team and preceptors attending an annual preceptor conference who had not previously participated in the Birkman Method faculty development program were invited to participate in this study.

Changes in self-awareness were determined through pre-intervention and post-intervention surveys. A pre-intervention survey instrument was distributed to faculty members and preceptors to establish baseline self-perceptions of personality traits, baseline self-confidence, and attitudes toward personality-type testing and training. The self-perception portion of the survey instrument asked respondents to select their communication (direct vs indirect) and behavior (people-oriented vs task-oriented) style under usual and stressful circumstances. They were also asked to select which types of communication and behavior they need from others to prevent stress. The self-confidence portion of the survey instrument asked respondents to rate their self-confidence, using a 5-point Likert scale, their ability to determine and explain their own communication and behavior styles, and their ability to perceive others' needs. The self-perception and selfconfidence questions are included in Tables 1 and 2. Demographic information was also collected as part of the pre-intervention survey. The investigator-generated survey tools used for the faculty and preceptor intervention were identical with the exception of one question regarding the importance of personality testing, which was tailored to the type of participant (faculty vs preceptor). These survey tools were slightly modified versions of instruments used previously to evaluate the impact of the Birkman Method assessment within a sample of pharmacy students. ${ }^{3}$ In that study, the internal consistency and reliability of the confidence survey items was evaluated, including a Cronbach alpha value of 0.69 for the preintervention survey tool and 0.76 for the post-intervention survey tool. ${ }^{3}$

After completing the pre-intervention survey, faculty and preceptors participated in the Birkman Method Development Intervention. The Birkman Method Faculty and Preceptor Development Intervention involved several components, including completing the Birkman Method assessment electronically, reviewing their detailed Birkman Method report, and attending a two-hour training program. Each group received the same two-hour training session, led by a certified Birkman Training Consultant, which provided in-depth instruction on interpreting and applying the results. Following the training sessions, each group participated in a one-hour activelearning session where they had the opportunity to apply the Birkman Method to commonly encountered scenarios. Training sessions were held separately for faculty members and preceptors so that each session could be modified to meet the specific needs of the audience. The faculty member's active-learning session was tailored to the participants' interactions as team members. They were divided based on the four usual communication and behavior results or color profiles (blue, red, yellow, and green). The four groups of faculty members were then asked to complete a critical-thinking game in which there was a common goal of promoting teamwork. Participants were asked to apply the knowledge they gained during the training session to interact with their colleagues based on their Birkman Method color profiles. The preceptors' active-learning session involved applying the principles through simulated student-preceptor interactions. This aspect of the learning focused on using the Birkman Method Coaching Page to tailor student feedback and rotation activities to optimize the interactions between preceptors and students on rotations. The Coaching Page was available to all participants who completed the Birkman Method assessment and offered a construct for how to coach an individual based on their unique communication and behavior styles.

Upon completion of the two-hour training and onehour active-learning sessions, both faculty members and preceptors were asked to complete a post-intervention survey instrument prior to leaving the training site. To ensure only internalized self-perceptions were measured and to avoid participants copying information directly from their reports, they were asked not to refer to their Birkman Method reports while completing the postintervention survey instrument. The pre- and post-intervention surveys were identical except for one additional question on the post-intervention survey instrument that asked participants how they would apply the training going forward.

Results of the Birkman Method assessment and surveys were de-identified and coded prior to analysis. The results of the pre- and post-intervention survey questions were compared for each participant. Additionally, all pre- and post- survey data were compared to each individual's Birkman Method color profiles, which served as 


\section{American Journal of Pharmaceutical Education 2019; 83 (7) Article 6920.}

Table 1. Pre- and Post-Intervention Results: Faculty Self-Perception and Confidence ( $\mathrm{n}=15)$

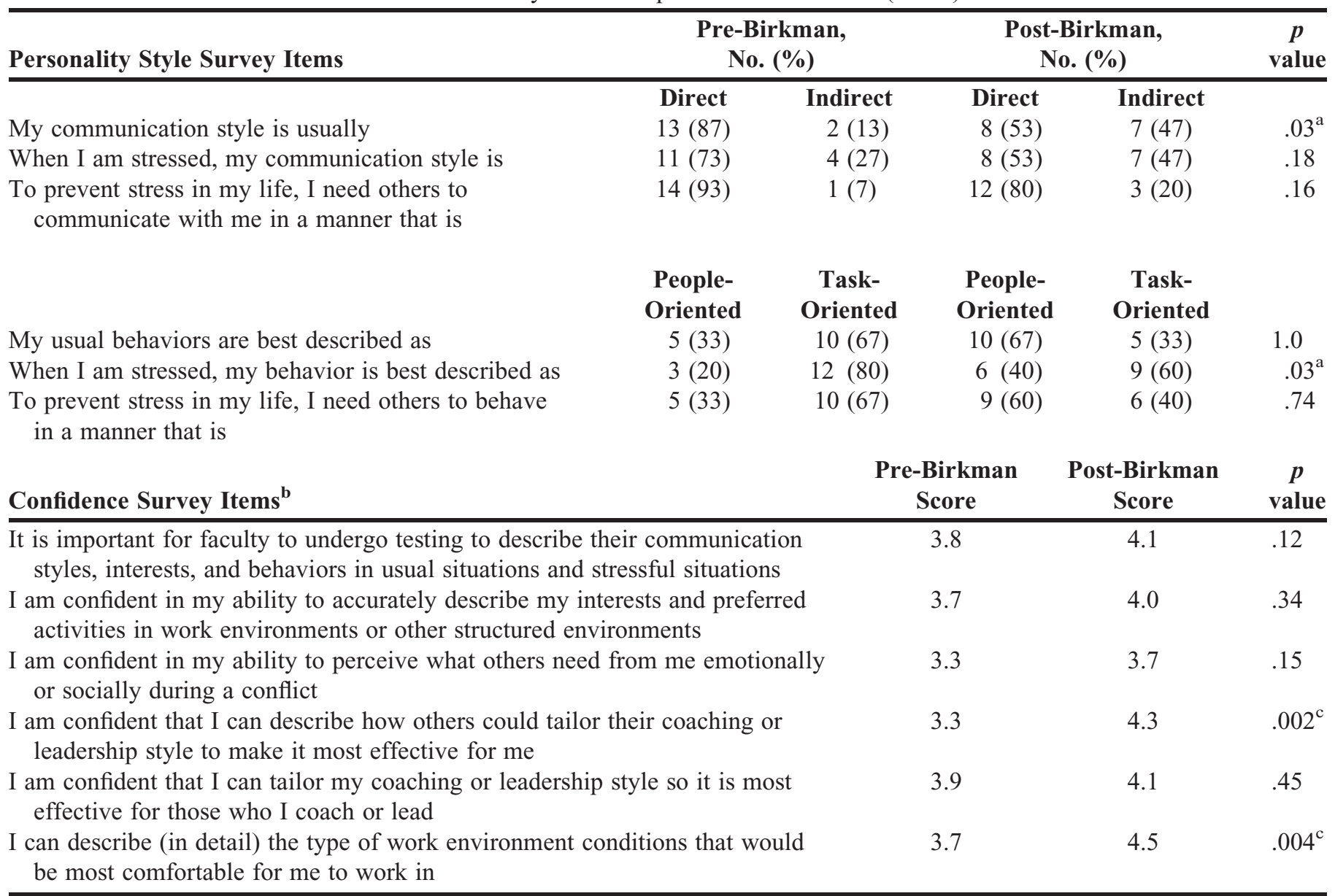

${ }^{a}$ Indicates a statistically significant finding, (McNemar test)

${ }^{\mathrm{b}}$ These items used the following Likert scale: $1=$ strongly disagree, $2=$ disagree, $3=$ neutral, $4=$ agree, $5=$ strongly agree

${ }^{\mathrm{c}}$ Indicates a significant finding, (Wilcoxon Signed Rank test)

a benchmark for accuracy to calculate the baseline and post-Birkman Self-Perception Accuracy Scores (SPAS). Faculty members and preceptors were allocated one point for each agreement between their Birkman Method color profiles and their self-perceptions. Using this investigator-generated tool, participants were scored on six parameters, so the maximum score for each individual was six points, accounting for self-perception accuracies of usual communication and behavior style, stressed communication and behavior styles, and the communication and behavior style needed to avoid stress. The changes in SPAS occurring as a result of the Birkman Method Intervention were calculated for participants by subtracting the preintervention survey SPAS from the post-survey SPAS. The SPAS tool has been published previously in a study documenting the outcomes of a student-focused Birkman Method intervention, with positive changes in SPAS also serving as an indicator of increased self-awareness in that study. ${ }^{3}$
The faculty development intervention was conducted in June 2014, and the preceptor intervention was conducted in March 2016. Eligible study participants were electronically recruited to participate in a follow-up survey in December 2016 to gauge the longitudinal impact of each intervention. Preceptors and faculty members were eligible for inclusion in the long-term follow-up survey if they had completed the Birkman Method testing and training during either the faculty development or preceptor development intervention and had released their results. Twelve faculty members who were also preceptors were excluded from the preceptor development portion of the study because of their prior exposure to the Birkman Method intervention. Completion of the pre- and post-intervention survey instruments was not required for inclusion in the longitudinal study. Through an electronic survey, participants were asked 11 Likert-scale questions to identify any sustained use of Birkman Method principles. Participants were also asked to evaluate any 


\section{American Journal of Pharmaceutical Education 2019; 83 (7) Article 6920.}

Table 2. Pre- and Post-Intervention Results: Preceptor Self-Perception and Confidence $(n=30)$

\begin{tabular}{|c|c|c|c|c|c|}
\hline \multirow[t]{2}{*}{ Personality Style Survey Items } & \multicolumn{2}{|c|}{$\begin{array}{l}\text { Pre-Birkman, } \\
\text { No. }(\%) \\
\end{array}$} & \multicolumn{2}{|c|}{$\begin{array}{l}\text { Post-Birkman, } \\
\text { No. }(\%) \\
\end{array}$} & \multirow[t]{2}{*}{$\begin{array}{c}p \\
\text { value }\end{array}$} \\
\hline & Direct & Indirect & Direct & Indirect & \\
\hline My communication style is usually & $28(93)$ & $2(7)$ & $14(47)$ & $16(53)$ & $.003^{\mathrm{a}}$ \\
\hline When I am stressed, my communication style is & $22(73)$ & $8(27)$ & $6(20)$ & $24(80)$ & $<.001^{\mathrm{a}}$ \\
\hline \multirow[t]{2}{*}{$\begin{array}{l}\text { To prevent stress in my life, I need others to } \\
\text { communicate with me in a manner that is }\end{array}$} & $29(97)$ & $1(3)$ & $24(80)$ & $6(20)$ & $.03^{\mathrm{a}}$ \\
\hline & $\begin{array}{c}\text { People- } \\
\text { Oriented } \\
16(53)\end{array}$ & $\begin{array}{l}\text { Task- } \\
\text { Oriented } \\
14(47)\end{array}$ & $\begin{array}{l}\text { People- } \\
\text { Oriented } \\
18(60)\end{array}$ & $\begin{array}{l}\text { Task- } \\
\text { Oriented } \\
12(40)\end{array}$ & 62 \\
\hline $\begin{array}{l}\text { When I am stressed, my behavior is best } \\
\text { described as }\end{array}$ & $10(00)$ & $28(93)$ & $13(43)$ & $17(57)$ & $.001^{\mathrm{a}}$ \\
\hline $\begin{array}{l}\text { To prevent stress in my life, I need others to } \\
\text { behave in a manner that is }\end{array}$ & $14(47)$ & $16(53)$ & $15(50)$ & $15(50)$ & .78 \\
\hline \multicolumn{3}{|l|}{ Confidence Survey Items ${ }^{b}$} & $\begin{array}{l}\text { Pre-Birkman } \\
\text { Score }\end{array}$ & $\begin{array}{l}\text { Post-Birkman } \\
\text { Score }\end{array}$ & $\begin{array}{c}p \\
\text { value }\end{array}$ \\
\hline \multicolumn{3}{|c|}{$\begin{array}{l}\text { It is important for preceptors to undergo testing to describe their communication } \\
\text { styles, interests, and behaviors in usual situations and stressful situations }\end{array}$} & 3.7 & 4.5 & $<.001^{\mathrm{c}}$ \\
\hline \multicolumn{3}{|c|}{$\begin{array}{l}\text { I am confident in my ability to accurately describe my interests and preferred } \\
\text { activities in work environments or other structured environments }\end{array}$} & 4.2 & 4.3 & .23 \\
\hline \multicolumn{3}{|c|}{$\begin{array}{l}\text { I am confident in my ability to perceive what others need from me emotionally } \\
\text { or socially during a conflict }\end{array}$} & 3.8 & 4.1 & .08 \\
\hline \multicolumn{3}{|c|}{$\begin{array}{l}\text { I am confident that I can describe how others could tailor their coaching or } \\
\text { leadership style to make it most effective for me }\end{array}$} & 3.8 & 4.1 & $.01^{\mathrm{c}}$ \\
\hline \multicolumn{3}{|c|}{$\begin{array}{l}\text { I am confident that I can tailor my coaching or leadership style so it is most } \\
\text { effective for those who I coach or lead }\end{array}$} & 3.8 & 4.4 & $.0004^{\mathrm{c}}$ \\
\hline \multicolumn{3}{|c|}{$\begin{array}{l}\text { I can describe (in detail) the type of work environment conditions that would } \\
\text { be most comfortable for me to work in }\end{array}$} & 4.2 & 4.6 & $.01^{\mathrm{c}}$ \\
\hline
\end{tabular}

${ }^{a}$ Indicates a statistically significant finding, (McNemar test)

${ }^{\mathrm{b}}$ These items used the following Likert scale: $1=$ strongly disagree, $2=$ disagree, $3=$ neutral, $4=$ agree, $5=$ strongly agree

${ }^{\mathrm{c}}$ Indicates a significant finding, (Wilcoxon Signed Rank test)

changes in self-confidence resulting from the intervention. The purpose of the follow-up survey was to assess for frequency of reflection on and communication with others about the Birkman Method principles, including incorporation of the principles into didactic or experiential teaching. Participants were also asked to rate their level of confidence that student experiences had improved as a result of the intervention. Additionally, they were asked to rate their agreement level with statements about their confidence level with regard to sufficiency of the training to improve their personal and professional lives. Finally, participants were asked to indicate if they felt it was important for pharmacy educators to undergo testing to better understand their communication styles, behaviors, and interests. The electronic survey was open for two weeks. After the survey was closed, a correlation analysis was performed to evaluate the associations between each item's response and the responses regarding the survey participant's confidence that the level of Birkman Method training received was sufficient. The questions included in the follow-up survey for faculty members and preceptors are described in Tables 3 and 4, respectively.

Descriptive statistics were used to summarize the demographic information for the faculty and preceptor participants in the Birkman Method faculty development interventions. Descriptive statistics were also used to summarize the longitudinal follow-up survey data. The Wilcoxon signed rank test was used to analyze the change in median post-Birkman self-confidence scores and the SPAS compared to baseline. The McNemar test was used to analyze the changes in self-perceived communication and behavior styles from baseline among faculty members and preceptors. Spearman correlation analysis was used to evaluate longitudinal survey data. All statistical analyses were performed using SAS for Windows, version 9.4 (SAS Institute, Inc, Cary, NC). 


\section{American Journal of Pharmaceutical Education 2019; 83 (7) Article 6920.}

Table 3. Longitudinal Follow-up Survey Results: Faculty Birkman Method Utilization and Confidence $(\mathrm{n}=5)$

\begin{tabular}{|c|c|c|c|}
\hline \multirow[b]{2}{*}{ Survey Items ${ }^{\mathrm{a}}$} & \multirow[b]{2}{*}{ Mean } & \multicolumn{2}{|c|}{$\begin{array}{l}\text { Correlation } \\
\text { Analysis }\end{array}$} \\
\hline & & Coefficient & $p$ value \\
\hline I reflect on my Birkman Method profile. & 3.0 & 0.88 & $.047^{\mathrm{b}}$ \\
\hline $\begin{array}{l}\text { I share the information I learned in the Birkman Method training with others in order to } \\
\text { describe my communication and behavior styles: }\end{array}$ & 3.2 & 0.80 & .10 \\
\hline $\begin{array}{l}\text { As a faculty member, I apply Birkman Method Principles in some capacity to improve } \\
\text { student experiences. }\end{array}$ & 3.0 & 1.0 & $<.001^{\mathrm{b}}$ \\
\hline I discuss Birkman Method principles within the didactic curriculum I teach. & 2.2 & 0.97 & $.007^{\mathrm{b}}$ \\
\hline I incorporate Birkman Method Principles into my experiential teaching or precepting. & 3.4 & 0.63 & .25 \\
\hline $\begin{array}{l}\text { I am confident that the exposure to the Birkman Method has improved my ability to manage } \\
\text { relationships in my professional life (faculty-faculty interactions or faculty-student interactions). }\end{array}$ & 3.6 & 0.97 & $.007^{\mathrm{b}}$ \\
\hline $\begin{array}{l}\text { I am confident that the exposure to the Birkman Method has improved my ability to manage } \\
\text { relationships in my personal life (family and friend interactions). }\end{array}$ & 3.6 & 0.63 & .26 \\
\hline I am confident that my exposure to the Birkman Method has improved my ability to manage stress. & 3.4 & 0.65 & .24 \\
\hline $\begin{array}{l}\text { I am confident that incorporating Birkman Method principles as a faculty member has led to } \\
\text { improved student experiences. }\end{array}$ & 3.6 & 0.97 & $.007^{\mathrm{b}}$ \\
\hline $\begin{array}{l}\text { I am confident that the level of training I received on the Birkman Method was sufficient } \\
\text { to allow me to effectively use the results in my professional and/or personal life. }\end{array}$ & 3.4 & Reference & - \\
\hline $\begin{array}{l}\text { It is important for pharmacy faculty to undergo testing to describe their communication styles, } \\
\text { interests, and behaviors in usual situations and stressful situations. }\end{array}$ & 4.2 & 0.65 & .24 \\
\hline
\end{tabular}

${ }^{a}$ The following Likert scale was used for the first five items in this table: $1=$ never, $2=$ rarely, $3=$ occasionally, $4=$ often, $5=$ never. The following Likert scale was used for the last six items in this table: $1=$ strongly disagree, $2=$ disagree, $3=$ neutral, $4=$ agree, $5=$ strongly agree

${ }^{\mathrm{b}}$ Indicates a statistically significant correlation exists

\section{RESULTS}

Of the 56 faculty members and 58 preceptors eligible, $38(67.9 \%)$ faculty members and $51(87.9 \%)$ preceptors participated in at least one phase of the study (Figure 1). Twenty-three faculty members and 37 preceptors completed the Birkman Method intervention, meaning that they participated in the Birkman Method testing and training program. Of these faculty participants, only 15 completed the entire study, meaning that they completed the pre- and post-intervention survey instruments, participated in the intervention (completed the Birkman Method selfassessment testing and attended the training program), and consented to release their Birkman results to the study team for analysis. Only faculty participants completing the entire study were eligible for inclusion in the analysis, with the exception of one faculty member who could not attend the one-hour active learning session but completed all other aspects of the study and was included. Of the 37 preceptors who completed the Birkman Method testing and training, 30 also completed all aspects of the study, meeting the criteria for inclusion in the analysis.

The mean age of the faculty members who completed all aspects of the study was 35.5 years $(\mathrm{SD}=8.7)$, and $60 \%$ were female. The majority of the faculty members had practiced pharmacy for five to 10 years $(53 \%)$. As shown in Figure 2, the most prevalent Birkman
Method type among the faculty members included in the analysis was blue usual (people-oriented) behavior and (indirect) communication type (40\%); blue needs and stress (people-oriented) behavior and (indirect) communication type (33\%); and blue (artistic/literary/ musical) interests (47\%).

Following the faculty development intervention, there were significant changes in self-perception in two parameters: usual communication style $(p=.03)$ and behavior style under stress $(p=.03)$. There was a significant decrease in the number of faculty members reporting a direct communication style post-intervention. Similarly, there was a significant decrease in the number of faculty members reporting a task-oriented behavior style. Twelve $(80 \%)$ participants reported a task-oriented style prior to the intervention, and $9(60 \%)$ participants reported a taskoriented style post-intervention (Table 1). Faculty members' average SPAS increased by 1.2 points from an initial score of 3.4 out of 6 possible points to 4.2 after the intervention $(p<.001)$.

With regard to the self-confidence assessment, faculty members experienced a significant increase in the self-confidence that they could describe how others could tailor coaching or leadership styles to best fit their needs. Their self-confidence in this parameter increased by 1.0 point on a 5-point Likert-based scale $(p=.002)$. All of the 


\section{American Journal of Pharmaceutical Education 2019; 83 (7) Article 6920.}

Table 4. Longitudinal Follow-up Survey Results: Preceptor Birkman Method Utilization and Confidence $(\mathrm{n}=7)$

\begin{tabular}{|c|c|c|c|}
\hline \multirow[b]{2}{*}{ Survey Items ${ }^{\mathrm{a}}$} & \multirow[b]{2}{*}{ Mean } & \multicolumn{2}{|c|}{$\begin{array}{l}\text { Correlation } \\
\text { Analysis }\end{array}$} \\
\hline & & Coefficient & $p$ value \\
\hline I reflect on my Birkman Method profile. & 2.9 & 0.41 & .36 \\
\hline $\begin{array}{l}\text { I share the information I learned in the Birkman Method training with others in order to } \\
\text { describe my communication and behavior styles. }\end{array}$ & 3.1 & 0.87 & $.01^{\mathrm{b}}$ \\
\hline $\begin{array}{l}\text { As a preceptor, I apply Birkman Method Principles in some capacity to improve student } \\
\text { rotation experiences. }\end{array}$ & 3.0 & 0.33 & .47 \\
\hline $\begin{array}{l}\text { I review students' Birkman Method profiles or coaching report to individualize my approach in } \\
\text { giving feedback to students. }\end{array}$ & 2.1 & 0.37 & .41 \\
\hline $\begin{array}{l}\text { I review students' Birkman Method profiles or coaching report to individualize the activities of } \\
\text { students on my rotation. }\end{array}$ & 2.1 & 0.37 & .41 \\
\hline $\begin{array}{l}\text { I am confident that the exposure to the Birkman Method has improved my ability to manage } \\
\text { relationships in my professional life (with students and with colleagues). }\end{array}$ & 3.7 & 0.90 & $.006^{\mathrm{b}}$ \\
\hline $\begin{array}{l}\text { I am confident that the exposure to the Birkman Method has improved my ability to manage } \\
\text { relationships in my personal life (with family and friends). }\end{array}$ & 3.4 & 0.87 & $.01^{\mathrm{b}}$ \\
\hline I am confident that the exposure to the Birkman Method has improved my ability to manage stress. & 3.3 & 0.85 & $.02^{\mathrm{b}}$ \\
\hline $\begin{array}{l}\text { I am confident that incorporating Birkman Method principles has improved rotation } \\
\text { experiences for my students. }\end{array}$ & 3.0 & 0.50 & .25 \\
\hline $\begin{array}{l}\text { I am confident that the level of training I received on the Birkman Method was sufficient to } \\
\text { allow me to effectively use the results in my professional and/or personal life. }\end{array}$ & 3.4 & Reference & - \\
\hline $\begin{array}{l}\text { It is important for pharmacy preceptors to undergo testing to describe their communication } \\
\text { styles, interests, and behaviors in usual situations and stressful situations. }\end{array}$ & 4.1 & 0.75 & .05 \\
\hline
\end{tabular}

${ }^{a}$ The following Likert scale was used for the first five items in this table: $1=$ never, $2=$ rarely, $3=$ occasionally, $4=$ often, $5=$ never. The following Likert scale was used for the last six items in this table: $1=$ strongly disagree, $2=$ disagree, $3=$ neutral, $4=$ agree, $5=$ strongly agree

${ }^{\mathrm{b}}$ Indicates a significant correlation exists

self-confidence assessment questions and data are also shown in Table 1.

The mean age of the preceptors who completed all aspects of the intervention was 39.6 years $(\mathrm{SD}=12.6)$, and the majority $(77 \%)$ were female. The most prevalent area of pharmacy practice was hospital (43\%), and the majority of the preceptors had been in pharmacy practice for $0-5$ years (37\%). As shown in Figure 2, the most prevalent Birkman Method usual type among preceptors was blue (people-oriented) behavior and (indirect) communication types $(53 \%)$. The majority of preceptors also exhibited blue (people-oriented) behavior and (indirect) communication needs and stress types (57\%); and blue (artistic/ literary/musical) interests (40\%).

For preceptors, there were significant changes in self-perception in four parameters: usual communication style, communication style under stress, behavior style under stress, and the communication needed in order to prevent stress $(p<.05$ for all parameters). As with the faculty sample, there was a significant decrease in preceptors reporting a direct communication style postintervention. As shown in Table 2, 28 (93\%) participants reported a direct style prior to the intervention, and 14 (47\%) reported a direct style post-intervention. A similar significant decrease occurred in preceptors reporting a direct communication style under stress, with 22 (73\%) participants reporting a direct communication style under stress in pre-intervention, and $6(20 \%)$ participants reporting a direct communication style under stress in postintervention. There was a decrease in preceptors reporting that direct communication style is needed by the subject to prevent stress. In the pre-intervention survey, 29 (97\%) preceptors perceived direct communication as the style they needed to prevent stress, while in the post-intervention survey, $24(80 \%)$ indicated they needed this style. There was a decrease in the number of preceptors reporting a task-oriented behavior style under stress, with 28 (93\%) preceptors reporting a task-oriented style under stress preintervention, and 17 (57\%) preceptors reporting this style post-intervention. Preceptors' mean SPAS significantly increased by 1.8 points, from 2.4 points out of 6 possible points pre-intervention to 4.2 points post-intervention $(p=.002)$. Preceptors experienced a significant increase from baseline of 0.6 points on a 5 -point Likert scale in self-confidence that they could tailor their coaching and leadership style to fit others' needs. A significant increase of 0.8 points occurred in preceptors' agreement with the importance of personality testing following the intervention.

Participation in all aspects of the study (eg, completion of pre- and post-intervention surveys and releasing 


\section{American Journal of Pharmaceutical Education 2019; 83 (7) Article 6920.}

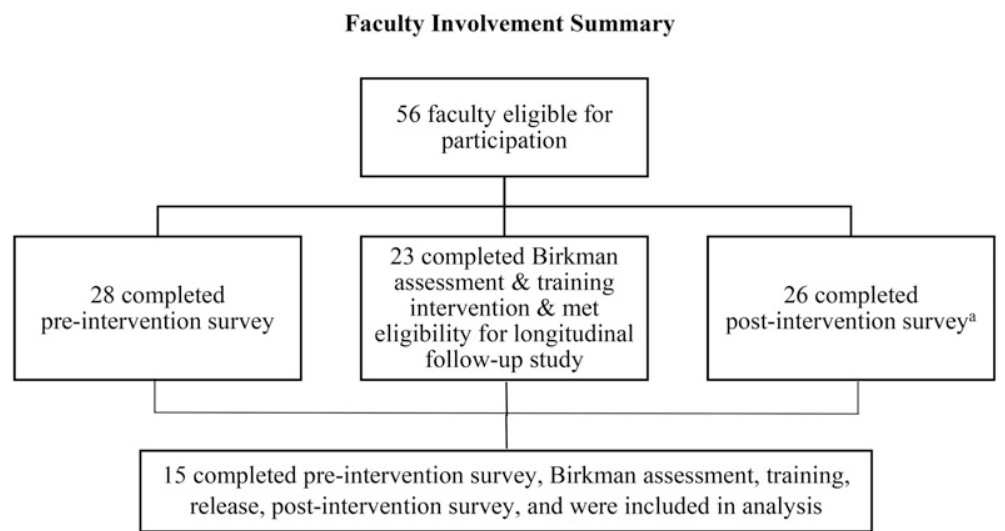

${ }^{\text {a }}$ Some faculty who did not complete the entire Birkman assessment \& training intervention still completed a post-intervention survey, but these surveys were excluded from the analysis, as shown above

Preceptor Involvement Summary

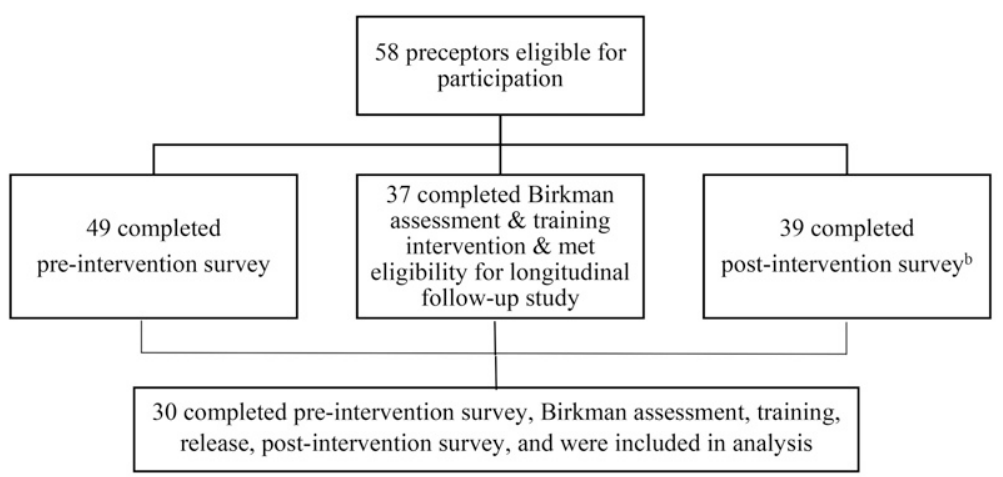

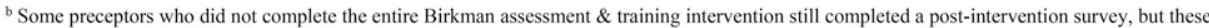
surveys were excluded from the analysis, as shown above

Figure 1. Faculty and Preceptor Involvement Summary

Birkman results to study personnel for analysis) was not required to be eligible for recruitment in the longitudinal follow-up survey. Participation in the Birkman Method intervention (completing the Birkman Method testing and

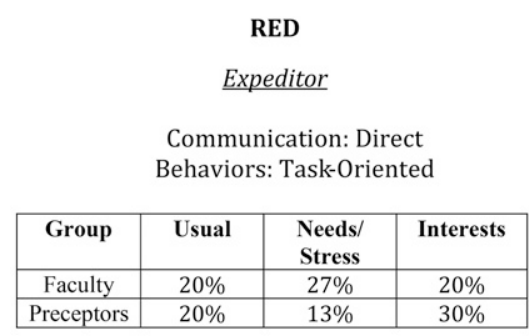

YELLOW

$\underline{\text { Administrator }}$

Communication: Indirect Behaviors: Task-Oriented

\begin{tabular}{|c|c|c|c|}
\hline Group & Usual & $\begin{array}{c}\text { Needs/ } \\
\text { Stress }\end{array}$ & Interests \\
\hline Faculty & $13 \%$ & $27 \%$ & $33 \%$ \\
\hline Preceptors & $3 \%$ & $23 \%$ & $23 \%$ \\
\hline
\end{tabular}

preceptor development training program) was required for inclusion in the longitudinal follow-up portion of the study, however. Thus, the 60 study subjects (23 faculty and 37 preceptors) completing the intervention were

\section{GREEN}

Communicator

Communication: Direct

Behaviors: People-Oriented

\begin{tabular}{|c|c|c|c|}
\hline Group & Usual & $\begin{array}{c}\text { Needs/ } \\
\text { Stress }\end{array}$ & Interests \\
\hline Faculty & $27 \%$ & $13 \%$ & $0 \%$ \\
\hline Preceptors & $23 \%$ & $7 \%$ & $7 \%$ \\
\hline
\end{tabular}

BLUE

Planner

Communication: Indirect Behaviors: People-Oriented

\begin{tabular}{|c|c|c|c|}
\hline Group & Usual & $\begin{array}{c}\text { Needs/ } \\
\text { Stress }\end{array}$ & Interests \\
\hline Faculty & $40 \%$ & $33 \%$ & $47 \%$ \\
\hline Preceptors & $53 \%$ & $57 \%$ & $40 \%$ \\
\hline
\end{tabular}

Figure 2. Faculty and Preceptor Birkman Types and the Birkman Lifestyle Grid 


\section{American Journal of Pharmaceutical Education 2019; 83 (7) Article 6920.}

invited to participate. Four of the email requests were undeliverable (three preceptors and one faculty member). Five faculty members and seven preceptors responded to the longitudinal survey. The mean scores for each of the items on both the faculty and preceptor surveys were generally above 3 , indicating that application of Birkman Method principles occurred at least sometimes, and that respondents were generally confident that the Birkman Method improved experiences for students and educators. One exception was that the majority of faculty members who responded indicated they rarely incorporated Birkman principles into their didactic teaching. On the preceptor survey, the mean scores indicated that they rarely reflected on their Birkman profiles after the preceptor development intervention and rarely used Birkman principles to give feedback or to individualize rotation activities. However, they indicated that they did use it at least sometimes, in some capacity.

The correlation analysis assessed for significant associations between the adequacy of the training received and the impact on student learning experiences, as well and educators' application of Birkman principles to teaching, their own personal and professional relationship management, and stress management. In the faculty group, there was a positive and significant correlation between the adequacy of Birkman Method training and application of Birkman Method principles in some capacity to improve student experiences $(r=1.0 ; p=<.001)$ as well as the faculty's confidence that incorporation of Birkman principles has improved student experiences $(r=0.97 ; p=.007)$. Similarly, there was a significant, positive correlation between the adequacy of training and the incorporation of Birkman Method principles in the didactic curriculum $(r=0.97 ; p=.007)$. The faculty's confidence in the improved ability to manage professional relationships ( $r=0.97 ; p=.007)$ was also positively correlated with confidence in the sufficiency of Birkman training. In the preceptor group, there was a significant positive correlation between confidence in the sufficiency of Birkman Method training and likelihood of sharing information gained through Birkman training $(r=0.87$; $p=.01$ ), confidence in the improved ability to manage professional relationships $(r=0.90, p=.006)$, manage personal relationships $(r=0.87, p=.01)$, and manage stress $(r=0.85, p=.02)$. Mean item scores and results of the correlation analysis evaluating the relationship between each of the longitudinal survey questions and the respondents' perceptions of the sufficiency of their Birkman Method training are shown in Tables 3 and 4 and a consolidated comparison of the correlation analyses including results for both preceptors and faculty members can be found in Table 5 .

\section{DISCUSSION}

Through the faculty development intervention, participants realized that they were significantly less direct in their usual communication style and more peopleoriented and less task-oriented in their stress behavior style than they perceived prior to this intervention. Ideally, this discovery will enable this group of faculty members to better understand how they are conveying information to others, and perhaps to adapt their usual communication style when appropriate to meet the needs of learners or professional colleagues. For example, faculty members who previously thought of themselves as direct communicators

Table 5. Longitudinal Combined Faculty and Preceptor Birkman Utilization and Confidence $(\mathrm{N}=12)$

\begin{tabular}{|c|c|c|c|}
\hline \multirow[b]{2}{*}{ Survey Items ${ }^{a}$} & \multirow[b]{2}{*}{ Mean (SD) } & \multicolumn{2}{|c|}{ Correlation Coefficient } \\
\hline & & $\begin{array}{l}\text { Faculty } \\
(n=5)\end{array}$ & $\begin{array}{c}\text { Preceptor } \\
(n=7)\end{array}$ \\
\hline \multicolumn{4}{|l|}{ Frequency of } \\
\hline Reflection on profile & $2.9(0.8)$ & $0.88^{\mathrm{b}}$ & 0.41 \\
\hline Sharing of profile & $3.2(1.3)$ & 0.80 & $0.87^{\mathrm{b}}$ \\
\hline Utilization to improve student experiences & $3.0(1.3)$ & $1.0^{\mathrm{b}}$ & 0.33 \\
\hline \multicolumn{4}{|l|}{ Confidence that } \\
\hline Program improved ability to manage professional relationships & $3.7(0.8)$ & $0.97^{\mathrm{b}}$ & $0.90^{\mathrm{b}}$ \\
\hline Program improved ability to manage personal relationships & $3.5(1.1)$ & 0.63 & $0.87^{\mathrm{b}}$ \\
\hline Program improved ability to manage stress & $3.3(0.8)$ & 0.64 & $0.85^{\mathrm{b}}$ \\
\hline Incorporation of program improved student experiences & $3.3(1.1)$ & $0.97^{\mathrm{b}}$ & 0.50 \\
\hline The level of training was sufficient & $3.4(1.1)$ & Reference & Reference \\
\hline
\end{tabular}




\section{American Journal of Pharmaceutical Education 2019; 83 (7) Article 6920.}

may now understand why a message they delivered may not have been received favorably or why their style of communication may not have been effective. The increases in self-awareness realized in this area could potentially improve the countless situations in which faculty members are providing instructions or delivering feedback to students or colleagues. Similarly, the change in faculty self-perceptions regarding emphasis on people rather than tasks under stress may allow them to better understand personal tendencies in the stressful situations. In general, the faculty members in our sample may now consider intentionally focusing on getting tasks done under stress, realizing their natural default is to focus on the people involved in completing the task rather than the task itself. Because faculty members are evaluated by teaching, service, and scholarly activity, efficiency and maximal productivity are essential to success. Thus, the significant increases in self-awareness seen in this study could potentially be transformative. Despite the fact that most faculty positions require two additional years of postgraduate training, which mandates self-evaluation and reflection, this intervention demonstrates that faculty members can still significantly improve their self-awareness of communication and behavior styles, particularly in stressful situations. Despite usually having advanced age, training, and experience (compared to students), faculty members may still need to grow in this area in order to effectively mentor students in the area of self-awareness. The improvements in faculty self-confidence with regard to personality-related preferences and coaching and leadership abilities further demonstrate that faculty development programs addressing the affective domain can facilitate growth.

Through the Birkman Method preceptor development intervention, preceptors also realized they were significantly less direct in their usual and stress communication style and less task-oriented in their stress behavior style than they perceived prior to Birkman testing and training. As with our faculty cohort, preceptors receiving the intervention may now better understand why their messages of instruction or feedback may not be received as they would anticipate. There was also a significant decline in their self-perceived need for others to communicate with them in a direct manner after Birkman testing and training. Although these individuals perceived themselves as able to receive straightforward feedback well, through the intervention, they learned that they may need those providing feedback to them to be more tactful in the delivery process. This could also incidentally impact the techniques used to deliver feedback to others. Noteworthy increases in self-awareness occurred following a Birkman Method Preceptor Development intervention that were numerically larger, but not significantly larger than the increases experienced by faculty members. This difference is likely related to the lower preceptor SPAS at baseline, but is an interesting finding. Our preceptor cohort was older in age than our faculty cohort, and prior research has demonstrated a negative relationship between age and self-perception accuracy scores. ${ }^{3}$ This highlights the importance of developing preceptor self-awareness as preceptors play a major role in providing formative feedback to students. This finding is also consistent with the significant increase in preceptors' confidence in their ability to tailor their coaching or leadership style to make it most effective for others. This study demonstrates that significant improvements in preceptors' self-awareness and self-confidence regarding communication and behavior styles, particularly in stressful situations, may also be necessary for preceptors to mentor students most effectively.

The correlation analysis conducted on longitudinal survey data revealed that both faculty members' and preceptors' confidence that they received sufficient Birkman Method training was associated with an improved perception of their ability to manage professional relationships, which is one of the primary goals of the Birkman Method intervention. In fact, for both faculty members and preceptors, the highest mean confidence scores were reported for items related to ability to manage professional relationships, personal relationships, and stress. Relationship management and stress management are key skills for faculty members and preceptors to embody for their own success, but ideally, it should also enable them to mentor students more effectively. Interestingly, the items that received the highest mean scores were those that addressed educators' personal use of the tool rather than the impact of their training on student experiences. Perhaps because of the brevity of the interventions, faculty members and preceptors had enough exposure to the Birkman Method to internalize the results but not fully apply the concepts within their teaching. Although the mean score on the adequacy of the training indicated that respondents generally felt it was sufficient, this aspect of the results raises the question as to whether the training was adequate for it to impact faculty members' and preceptors' interaction with students. Perhaps a more longitudinal approach in the faculty and preceptor development intervention would have reinforced concepts over time, thus enabling preceptors to apply the information not only to themselves but also to their students. In general, mean scores from the faculty survey were numerically larger than those from the preceptor survey, with faculty indicating slightly more frequent incorporation of Birkman principles than preceptors. This may be because preceptors indicated they rarely applied Birkman Method 


\section{American Journal of Pharmaceutical Education 2019; 83 (7) Article 6920.}

principles to individualize feedback or activities for students. The lowest mean score among faculty respondents occurred for the item evaluating the frequency of discussion of Birkman principles within the didactic curriculum, although this is not surprising given the highly clinical nature of the didactic curriculum content. Within the preceptor and faculty longitudinal follow-up survey results, the mean score of one item addressing the importance of conducting this type of intervention did decline slightly in the longitudinal follow-up survey compared to the mean score immediately following Birkman testing and training. However, this item had the highest mean score overall on both the preceptor and faculty follow-up surveys, indicating that educators still found the training important. Perhaps the decline could be attributable to response shift bias.

In summary, both faculty members and preceptors benefitted from this intervention through significant increases in self-awareness. Self-confidence also increased for both faculty members and preceptors in various ways. While the improvement in self-awareness in faculty members was numerically smaller than that in preceptors, the between-group differences were not significant. This indicates that pharmacy educators in both didactic and experiential settings can benefit from self-awareness directed development in order to be more equipped to teach and mentor students in this arena.

Also, the most prevalent Birkman type among both faculty and preceptor participants, was the blue Birkman type for usual and stressed communication and behavior styles and the blue interest type. Blue Birkman types are people-oriented and indirect, and are also described as characteristically reflective. According to a white paper comparing the Myers-Briggs personality test to the Birkman Method, there should be an equal distribution of Birkman types throughout the population, but this is not reflected within our sample of pharmacy faculty members and preceptors. ${ }^{29}$ This finding is similar to the Birkman type demonstrated previously in a student sample in which the majority of students had a blue usual (indirect) communication and (people-oriented) behavior style, and blue needs and stress behavior type. ${ }^{3} \mathrm{Al}-$ though further validation in other samples of pharmacy educators would be needed to draw more definitive conclusions, perhaps the prevalence of the blue Birkman type is a reflection of the people-oriented nature of individuals who are attracted to careers in pharmacy and pharmacy education.

As mentioned previously, the investigator-generated tools and instruments that were employed during this study were also used in the previously published Birkman Method student intervention. ${ }^{3}$ However, despite the measures used to assess the reliability of the internal consistency of some of the instruments in that study (eg, calculation of Cronbach alpha), these instruments have not been externally validated, which is a limitation. Additionally, the possibility of over-estimation of selfawareness improvements using the SPAS tool cannot be ruled out. The SPAS tool measures changes in selfperceptions occurring after Birkman Method testing and training. Ideally, this change reflects internalized changes in self-perceptions rather than a direct reporting of Birkman Method results by participants. Study personnel instructed participants to avoid referring to their Birkman results when completing the post-intervention survey so that only truly internalized self-perception changes would be captured in the post-intervention survey. Despite these efforts, the possibility of inflated self-perception accuracy scores post-intervention still exists. Another limitation of this study was the difference in the Birkman Method active-learning session (one hour) content provided to preceptors and faculty members. This portion of each intervention differed in nature based on each audience and their roles in student education. While these differences may somewhat limit direct comparison of results for research purposes, they were necessary to ensure the relevance of the experience to educators. The difference in the nature and focus of each interactive session explains why the groups significantly increased their selfconfidence in different ways. For the faculty members, the interactive session focused on team building and communication. This is probably why faculty members experienced a greater increase in self-confidence in their abilities to describe their needs to others and to describe their preferred working environments. Preceptors experienced a significant increase in self-confidence in their abilities to tailor their own coaching and leadership styles to fit the needs of those they coach or lead. This is likely reflective of the focus of the preceptors' interactive session emphasizing student-preceptor interactions and the Birkman Method Coaching Page. The small number of participants, particularly in the secondary, longitudinal component of the study, also limits the ability to generalize some of the findings or interpret the results without significant differences. From a logistics standpoint, electronic recruitment was the most practical option for disseminating the longitudinal follow-up survey. This method of survey dissemination is generally associated with extremely low response rates. However, our rate was nearly three times larger than the typical response rate for electronically disseminated surveys reported in the literature. ${ }^{30}$ Despite this limitation, we feel that the longitudinal survey data add value in terms of the long-term implications of the intervention. 


\section{American Journal of Pharmaceutical Education 2019; 83 (7) Article 6920.}

An additional limitation of the longitudinal portion of the study included the potential for differential recall bias between the faculty respondent group and the preceptor respondent group because of the differences in time intervals between delivery of the intervention to each of the respondent groups and completion of the longitudinal survey.

\section{CONCLUSION}

Involvement of faculty members and preceptors is vital to the development of self-awareness in students because they are directly responsible for this student outcome. This study provides outcomes of the first example of a pharmacy faculty and preceptor development program focusing on self-awareness. Our results demonstrate that both faculty members and preceptors have opportunities to improve their self-awareness and can benefit from development interventions to assist them with this growth. They also demonstrate that longitudinally, preceptors and faculty members may feel better equipped to manage relationships and stress after receiving Birkman testing and training, particularly when they perceive the level of training to be adequate. Instituting professional development programs such as the Birkman Method intervention can help create a culture of self-awareness at schools and colleges of pharmacy, beginning with the key educational stakeholders: faculty members and preceptors.

\section{ACKNOWLEDGMENTS}

Funding for faculty and preceptor Birkman Method testing and training was provided by the Kennedy Pharmacy Innovation Center at the University of South Carolina.

\section{REFERENCES}

1. Krathwohl DR, Bloom BS, Masia BB, eds. Taxonomy of Educational Objectives. The Classification of Educational Goals. Handbook II: Affective Domain. New York, NY: David McKay Co., Inc., 1964.

2. Accreditation Council for Pharmaceutical Education. Accreditation standards and key elements for the professional program in pharmacy leading to the Doctor of Pharmacy degree (Standards 2016). https://www.acpe-accredit.org/pdf/ Standards2016FINAL.pdf. Published February 2015. Accessed August 24, 2019.

3. Maxwell WD, Grant AD, Fabel PH, et al. Impact of the Birkman method assessment on pharmacy student self-confidence, selfperceptions, and self-awareness. Am J Pharm Educ. 2016;80(9):Article 148.

4. Lovas JG, Lovas DA, Lovas PM. Mindfulness and professionalism in dentistry. $J$ Dent Educ. 2008;72(9):998-1009.

5. Novack DH, Epstein RM, Paulsen RH. Toward creating physician-healers: fostering medical students' self-awareness, personal growth, and well-being. Acad Med. 1999;74(5):516-520.
6. Latif DA. Using emotional intelligence in the planning and implementation of a management skills course. Pharm Educ. 2004; 4 (2):81-89.

7. McMullan M. Using portfolios for clinical practice learning and assessment: the pre-registration nursing student's perspective. Nurse Educ Today. 2008;28(7):873-879.

8. Zeind CS, Zdanowicz M, Macdonald K, et al. Developing a sustainable faculty mentoring program. Am J Pharm Educ. 2005;69(5): Article 100.

9. Jackevicius CA, Le J, Nazer L, et al. A formal mentorship program for faculty development. Am J Pharm Educ. 2014;78(5):Article 100.

10. Haines ST. The mentor-protégé relationship. Am J Pharm Educ. 2003;67(3):Article 82.

11. Nagarur A, O’Neill RM, Lawton D, et al. Supporting faculty development in hospital medicine: design and implementation of a personalized structured mentoring program. J Hosp Med.

2018;13(2):96-99.

12. Farrell SE, Digioia NM, Broderick KB, et al. Mentoring for clinician-educators. Acad Emerg Med. 2004;11(12):1346-1350. 13. Dobie S. Viewpoint: reflections on a well-traveled path: selfawareness, mindful practice, and relationship-centered care as foundations for medical education. Acad Med. 2007;82(4): 422-427.

14. Hatem DS, Barrett SV, Hewson M, et al. Teaching the medical interview: methods and key learning issues in a faculty development course. J Gen Intern Med. 22(12):1718-1724.

15. Pololi LH, Frankel RM. Humanising medical education through faculty development: linking self-awareness and teaching skills. Med Educ. 2005;39(2):154-162.

16. Gordon GH, Rost K. Evaluating a faculty development course on medical interviewing. In: Lipkin M, Putnam SM, Lazarre A, Carroll JG, Frankel RM, eds. The Med Interview. Frontiers of Primary Care. New York, NY: Springer; 1995.

17. Boyle CJ, Morgan JA, Layson-Wolf C, et al. Developing and implementing an academy of preceptors. Am J Pharm Educ. 2009;73(2): Article 34.

18. Vos SS, Trewet CB. A comprehensive approach to preceptor development. Am J Pharm Educ. 2012;76(3):Article 47.

19. Sonthisombat P. Pharmacy student and preceptor perceptions of preceptor teaching behaviors. Am J Pharm Educ. 2008;72(5):Article 110.

20. Robles J, Cox CD, Seifert CF. The impact of preceptor and student learning styles on experiential performance measures. Am J Pharm Educ. 2012;76(7):Article 128.

21. Stebbins MR, Cutler TW, Corelli RL, et al. Medicare part d community outreach train-the-trainer program for pharmacy faculty. Am J Pharm Educ. 2009;73(3):Article 53.

22. Waddell J, Spalding K, Navarro J, et al. Integrating a career planning and development program into the baccalaureate nursing curriculum: part iii. Impact on faculty's career satisfaction and confidence in providing student career coaching. Int J Nurs Educ Scholarsh. 2015;12(1):183-190.

23. Lu W, Mylona E, Lane S, et al. Faculty development on professionalism and medical ethics: the design, development and implementation of objective structured teaching exercises (OSTEs). Med Teach. 2014;36(10): 876-882.

24. Kassam R, Kwong M, Collins JB. An online module series to prepare pharmacists to facilitate student engagement in patientcentered care delivery: development and evaluation. Adv Med Educ Pract. 2012;3:61-71. 


\section{American Journal of Pharmaceutical Education 2019; 83 (7) Article 6920.}

25. Kamolo E, Vernon R, Toffoli L. A critical review of preceptor development for nurses working with undergraduate nursing students. Int J Caring Sci. 2017;10(2):1089-1100.

26. Mookherjee S, Monash B, Wentworth KL, et al. Faculty development for hospitalists: structured peer observation of teaching. J Hosp Med. 2014;9(4):244-250.

27. Fink SB, Capparell S. The Birkman Method: Your Personality at Work. $1^{\text {st }}$ ed. San Francisco, CA: John Wiley \& Sons, Inc., 2013: $13-48$.
28. Birkman RW, Elizondo F, Lee LG, et al. The Birkman Method Manual. Houston, TX: Birkman International, Inc., 2008:145-193. 29. White Paper: A Comparison Between The Birkman Method and The Myers-Briggs Type Indicator (MBTI). The Birkman Method website. https://birkman.com/wp-content/uploads/2016/05/

TBM_and_MBTI_Comparison.pdf. Accessed December 14, 2017. 30. Hardigan PC, Popovici I, Carvajal MJ. Response rate, response time, and economic costs of survey research: a randomized trial of practicing pharmacists. Res Social Adm Pharm. 2016;12(1):141-148. 